\title{
Violación de los derechos humanos en Cuba: ¿Baja o alta intensidad?
}

Human rights abuses in Cuba: High or low intensity?

\author{
Laura Tedesco \\ Saint Louis University \\ Itedesco@slu.edu \\ Rut Diamint \\ Universidad Torcuato Di Tella \\ rutd@utdt.edu
}

Cómo citar/Citation: Tedesco, Laura y Rut Diamint. 2020. «Violación de los derechos humanos en Cuba: ¿Baja o alta intensidad?». Deusto Journal of Human Rights, n. 5: 215-241. doi: http://dx.doi.org/10.18543/ djhr.1794

Sumario: Introducción. 1. ¿Violaciones de baja intensidad? 2. Encuadre metodológico. 3. Legalidad ignorada. 4. Derechos humanos y seguridad. 5. La cuestión de los regulados. 6. Detenciones arbitrarias. 7. Las Damas de Blanco. 8. Libertad de expresión. Conclusiones. Referencias bibliográficas.

Resumen: El artículo ofrece un análisis de la situación de los derechos humanos en Cuba teniendo en cuenta el marco legal vigente con la reciente aprobación de una nueva Constitución. Cuando Raúl Castro asumió la Presidencia, implementó cambios económicos que no se trasladaron en lo político. Por el contrario, las violaciones a los derechos humanos continuaron y en algunos casos se han incrementado. La investigación que se presenta en estas páginas está basada en entrevistas realizadas entre 2016 y 2019 en distintas ciudades de Cuba y en un seguimiento de las informaciones publicadas en distintos medios sobre las detenciones en la isla. La cuestión que se trata de responder refiere a la intensidad de las violaciones de derechos humanos que se registran en Cuba.

Palabras clave: Cuba, derechos humanos, democracia, Constitución, libertad de expresión

Abstract: The article offers an analysis of the situation of human rights in Cuba, taking into account the legal framework established by the new 
Constitution. When Raul Castro took office, he implemented economic changes which were not translated into the political sphere. On the contrary, human rights violations continued, and in some cases have increased. The research presented here is based on interviews conducted between 2016 and 2019 in different cities in Cuba and the follow-up of information in different media sources on illegal arrests on the island. The main goal is to ascertain the intensity of human rights violations in Cuba.

Keywords: Cuba, human rights, democracy, Constitution, freedom of expression 


\section{Introducción}

El significado de la Revolución Cubana de 1959 era, desde el punto de vista humanitario, un progreso hacia la igualdad de los ciudadanos y un medio para liberarlos de un estado de dominación material y política. Basta con recordar el discurso del comandante Fidel Castro en su llegada triunfal a La Habana: «En la época de dictadura la opinión pública no es nada, pero en la época de la libertad la opinión pública lo es todo, y los fusiles se tienen que doblegar y arrodillar ante la opinión pública» (Castro 1959). Sin duda, desde los años 60, la Revolución expandió derechos económicos y sociales, inspiró otras luchas regionales, creó mitos y héroes intocables, pero existen controversias sobre el respeto a las libertades civiles y de expresión. Sesenta años después, entre los legados de la Revolución se encuentra la falta de reconocimiento a la protección de los derechos humanos de los ciudadanos que ejercen libertad de pensamiento.

Este artículo analiza diferentes problemas de los derechos humanos en Cuba. Estudiar la situación de los derechos humanos en Cuba presenta dificultades que hemos intentado superar. La información es escasa y, en muchos casos, ideológicamente subjetiva. Es necesario poder desmitificar los discursos de los extremos políticos históricamente enfrentados. Unos estudios enfatizan el acceso a la educación y a la salud para todos los cubanos, tal como expresa el diario oficial Granma: "Junto a la educación, el acceso a los servicios de salud constituye uno de los derechos humanos más esenciales, pues determina sobre las posibilidades de vida o muerte de las personas» (Quevedo 2014). Otros ponen el énfasis en la represión sobre aquellos que piensan diferente.

Los defensores del régimen argumentan que en Cuba nunca se dieron violaciones a los derechos humanos similares a las de otros países latinoamericanos; por ejemplo, se insiste que en Cuba nunca se torturó masivamente a ciudadanos, ni se apropiaron de los hijos de detenidos ilegales. Las fuerzas armadas y de seguridad no hurtaron los bienes de aquellos a quienes apresaron. Sin embargo, del lado opositor, se argumenta que existieron violaciones, muy especialmente en los primeros años revolucionarios.

El objetivo de este artículo es analizar las violaciones a los derechos humanos desde que Fidel Castro dejó de ejercer el gobierno en 2006. La apertura económica propiciada por Raúl Castro, el establecimiento de distintos tipos de propiedad, el surgimiento de los cuentapropistas y el restablecimiento de relaciones diplomáticas con los EE.UU. en 2014 alentaron ideas sobre cambios políticos. No obstante, esa apertura económica no estuvo acompañada ni de cambios políticos ni de 
libertades civiles. Por el contrario, el artículo confirma que los cambios, incluso con la aprobación de la reforma a la Constitución en febrero de 2019, no modificaron la persecución política y la ausencia de alternativas al Partido Comunista. Esa imagen de apertura presente desde 2014 oculta un atropello constante y creciente a la libertad de expresión y de movimiento.

En los últimos años se han incrementado las detenciones injustificadas de periodistas independientes, artistas o activistas sociales, como así también las trabas para movilizarse a reuniones o encuentros a nivel local, nacional o internacional, y los encarcelamientos sin juicio, tal como se especifica en el punto siguiente.

Un efecto llamativo de estas circunstancias es que, a pesar de la publicación de cifras que confirman la persecución a cualquier tipo de crítica o disidencia con el oficialismo, son pocos los gobiernos que condenan a Cuba por estas violaciones a los derechos humanos. Aún peor, los países u organismos internacionales que denuncian abusos son tildados de pro fascistas gracias a una propaganda muy bien orquestada del gobierno cubano.

El artículo comienza analizando el marco conceptual e histórico en base al cual se desprende el supuesto de este trabajo: la violación de los derechos humanos en Cuba es una política sistemática del gobierno que se traduce en actos abusivos contra la libertad de expresión y circulación de los ciudadanos. Estas violaciones no reciben la atención debida de la comunidad internacional. El punto siguiente describe el encuadre metodológico de la investigación llevada a cabo. El tercer apartado se ocupa de la cara legal que esconde una realidad diferente ya que muchos de los derechos que otorga la Constitución son violados sistemáticamente por el Estado. Los siguientes puntos detallan casos específicos que permiten comprobar las violaciones a los derechos humanos. Así, el apartado 4 explica la relación de los derechos humanos con los aparatos de seguridad. El 5 describe el problema de los llamados «regulados». El caso siguiente es el de las detenciones arbitrarias. El punto 7 expone la situación de las «Damas de Blanco». En el apartado 8 se delinean las cuestiones relativas a la libertad de expresión. Finalmente presentamos los comentarios conclusivos del artículo.

\section{1. ¿Violaciones de baja intensidad?}

Una extensa literatura ha dado cuenta de los abusos a los derechos humanos en América Latina. Las organizaciones de la sociedad 
civil emprendieron una lucha denodada por lograr el retorno a la democracia (Leis 1989, 21-24). Jelin $(2003,5)$ grafica claramente ese proceso que se asienta en los años 70:

Lo que ocurrió en ese período fue la incorporación del marco de los derechos humanos en la lucha anti-dictatorial. Antes, la dominación y las luchas sociales y políticas eran interpretadas en términos de lucha de clases o de revoluciones nacionales. La incorporación de la clave «violaciones a los derechos humanos» fue, en ese marco, una verdadera revolución paradigmática.

Y agrega refiriéndose a las décadas de los años 80 y 90: «las demandas de los movimientos de mujeres y de los movimientos de derechos humanos fueron incorporadas en la agenda social y política de las transiciones» (Jelin 2003, 8). Aquellas violaciones fueron masivas.

En el caso de Cuba no existen datos que indiquen violaciones masivas sino acciones gubernamentales que afectan la vida cotidiana de ciudadanos que tienen un pensamiento distinto del gobierno y ejercen su libertad de pensamiento y expresión como periodistas, opositores políticos o activistas sociales. ¿Se puede decir, entonces, que se trata de violaciones a los derechos humanos de baja intensidad? Boaventura de Sousa $(2002,69)$ considera que «los derechos humanos de baja intensidad son la otra cara de la democracia de baja intensidad». Tomamos el término basándonos en la literatura sobre democracia. Esa literatura se ha ocupado de las llamadas democracias de baja intensidad, que se caracterizan por cumplir con las reglas procesales que permiten cierta oposición política, pero su desempeño es más limitado respecto de las libertades individuales o la división de poderes. Como sostienen Gills et al. (1994, 8-9): «la paradoja de la democracia de baja intensidad es que un régimen civil conservador puede seguir políticas sociales y económicas severas, e incluso represivas, con más impunidad y menos resistencia popular que un régimen abiertamente autoritario».

Krujit (2001, 409-430) considera que las democracias de baja intensidad son «las democracias cuyos ciudadanos están vigilados, cuyos políticos están asesorados, cuyos legisladores son tímidos y cuyos jueces temen». Y agrega:

Estas son democracias cuyas instituciones democráticas (gobiernos civiles, partidos políticos, parlamentos y poderes judiciales independientes) y la sociedad civil (asociaciones empresariales, el movimiento laboral, asociaciones populares y el circuito de ONGs) parecen estar suspendidas en un estado de «adolescencia permanente» (Krujit 2001, 409-430). 
Ello provoca «la amenaza de la mano dura de los educadores militares nacionales» (Krujit 2001, 409-430). Guillermo O'Donnell agrega otra dimensión similar. Dice: «Un estado que no puede hacer cumplir su legalidad sostiene una democracia con una ciudadanía de baja intensidad» (O'Donnell 1993, 14).

Partiendo de una diferencia fundamental, ya que en Cuba no hay democracia, ni de alta ni de baja intensidad, queremos trasladar el concepto para analizar otro aspecto de la realidad cubana: ¿es posible considerar que el gobierno viola los derechos humanos en un nivel de baja intensidad porque hace un uso limitado de la fuerza?

Ya había señalado Foucault $(2002,213)$ que los discursos y las prácticas disciplinarias operan sobre todos los planos de lo social, por medio de prácticas institucionales específicas. Los ciudadanos internalizan esa disciplina, incluso ante el hecho que no se apliquen directamente sobre su persona, pero que se reconocen como una política posible. El individuo vive con temor, pues se instala la noción que el Estado, o un representante del Estado, tiene la facultad de castigar, hay certidumbre de ser castigado. Cualquiera puede ser identificado como un peligro social, ya que una manifestación contraria se traduce como una afrenta al régimen, un quebrantamiento de las reglas significa un ataque al presidente. Las técnicas de coerción al individuo son leves pero efectivas. Son la expresión de las relaciones de poder a las que están sometidos los habitantes. El objetivo es corregir, hacer dócil al individuo. En una de las entrevistas en La Habana un joven nos dijo «no te matan, pero no te dejan vivir».

En el caso de violaciones masivas de derechos humanos, tanto organismos internacionales como organizaciones de la sociedad civil reaccionan fuertemente y cuestionan a esos gobiernos. Ese fue el caso durante las dictaduras militares en América Latina, las atrocidades durante la guerra de los Balcanes o el genocidio en Ruanda. En Cuba no hay evidencias de desapariciones ni genocidios. Sin embargo, existe escasez de alimentos, precariedad de las viviendas, raquitismo de los salarios y una constante persecución y encarcelamiento de aquellos que piensan distinto y se atreven a expresar sus opiniones. Las redes sociales se están convirtiendo en una ventana transparente donde se pueden ver los abusos sobre los derechos civiles y políticos y el deterioro de los derechos sociales. De todas maneras, la reacción internacional frente a esta situación es casi nula.

Amnistía Internacional (2018) especificó que: «un gran número de activistas, tanto políticos como en favor de los derechos humanos, continuaban siendo objeto de hostigamiento, intimidación y detención 
arbitraria». Por su parte, la Comisión Interamericana de Derechos de Derechos Humanos (CIDH) informó:

Las persistentes restricciones a los derechos políticos, de reunión y asociación, y a la libertad de expresión y de difusión del pensamiento, además de las vulneraciones masivas a los derechos a la libertad, a la seguridad e integridad de la persona, a la protección contra la detención arbitraria, a la inviolabilidad del domicilio y circulación de la correspondencia, a la residencia y tránsito, a las garantías judiciales mínimas y a la protección judicial, continúan limitando de manera sistemática los derechos humanos de los habitantes en Cuba, en particular, en perjuicio de personas defensoras de derechos humanos, líderes sociales y políticos, y periodistas independientes, así como afrodescendientes, mujeres, personas LGTBI, entre otros grupos históricamente vulnerables. (Lanza 2018)

Human Rights Watch (2019) reportó que: «la cantidad de detenciones arbitrarias de corta duración de defensores de derechos humanos, periodistas independientes y otras personas fue sustancialmente menor que en 2017 , pero igualmente alta, y hubo más de 2.000 denuncias de detenciones arbitrarias entre enero y agosto de 2018». Hay denuncias concretas de organismos especializados; sin embargo, el alto grado de polarización deriva en que algunos medios de comunicación se hagan eco de estas informaciones y otros las ignoren.

Reporteros Sin Fronteras también ha informado acerca de las prohibiciones sobre la prensa independiente y la falta de cumplimiento del gobierno cubano con los compromisos internacionales (Beaulieu 2014, 472).

Aquellos países gobernados por partidos de izquierda nunca han condenado las acciones del gobierno de Cuba. Hay un respeto histórico por aquella revolución que supo enfrentarse al imperialismo norteamericano en plena Guerra Fría y por un pueblo que ha sobrevivido 60 años a un bloqueo comercial, económico y político por parte de la mayor potencia del mundo. El gobierno cubano ha convencido a sus compatriotas y a una izquierda en el exterior de los éxitos de la revolución, como si fuera un dogma de fe, victimizándose ante la amenaza siempre virtual de la invasión estadounidense. Sobre ello ha dicho el escritor Leonardo Padura, que sus obras son: "una reflexión sobre la gran perversión de esa utopía» (Stefanoni 2013). En este contexto, los gobiernos de izquierda miran para otro lado cuando el gobierno de los Castro o, el de Miguel Díaz Canel, atropella los derechos humanos. Más aún, cuando el nivel de ese atropello puede considerarse de baja intensidad. 


\section{Encuadre metodológico}

Esta sección presenta las particularidades metodológicas de esta investigación cualitativa, un estudio de caso basado en entrevistas. Entre 2016 y 2019 realizamos cuatro viajes a Cuba donde pudimos realizar 64 entrevistas en La Habana, Cienfuegos y Santa Clara. La selección de entrevistas, en este caso específico, no podía responder a un modelo claro de una muestra «en cadena» o de «intención». El proceso de indagación ha sido inductivo, proveniente de las interacciones con los participantes. En un país como Cuba, se presentan importantes dificultades para seguir una estricta metodología de estudio: se realizan las entrevistas que se pueden realizar (en algunos casos los cubanos o cubanas no asistían a la cita porque habían sido arrestados), se preguntan cuestiones que no van a incomodar al entrevistado para poder continuar la conversación, las entrevistas no se graban y se toman notas inmediatamente después de la entrevista para que el entrevistado no sienta temor.

Entrevistamos a militares retirados, periodistas de medios oficiales y medios independientes, artistas independientes, disidentes con vigilancia en las puertas de sus casas, académicos con puestos en universidades públicas, médicos con trabajos en hospitales públicos, activistas relacionados con la iglesia católica, seguidores de la religión Yoruba, directores de teatro y militares en actividad que confesaban poner su carrera en riesgo por encontrarse con nosotras.

En la mayoría de los casos, es necesario establecer un vínculo de confianza con el entrevistado. En una sociedad como la cubana prevalece el miedo y la desconfianza como nos lo hicieron saber muchas veces los entrevistados y los cubanos y cubanas que participaron en los eventos organizados.

Las entrevistas eran individuales y en profundidad, con el objetivo de encuadrar el estudio desde el punto de vista de los participantes. Debido a las limitaciones para acceder a internet, la mayoría de las personas conectadas solicitaban que las llamáramos por teléfono al llegar a la isla. Con el fin de ampliar la lista de entrevistados, a cada uno le pedíamos sugerencias y contactos. En otras ocasiones, íbamos a diferentes actividades artísticas, periodísticas o culturales y nos acercábamos a las personas que nos resultaban interesantes por su participación en la actividad. En todos los casos, contábamos con un cuestionario prefijado, para garantizar el rigor del trabajo científico, pero raramente se completaba ya que los entrevistados tenían su propia agenda o urgencias (Cádena-Iñíguez 2017, 1612).

Por otra parte, recabar información sobre violaciones de los derechos humanos en Cuba es complejo, y en cierta medida peligroso. Toda 
la información que se encuentra puede haber sido manipulada con intenciones ideológicas de favorecer o desfavorecer al gobierno cubano. Vale acotar que las entrevistas referían a cuestiones más amplias que los derechos humanos. Ni las entrevistas, ni las estadísticas por sí mismas presentan la complejidad de la situación de los derechos humanos en la isla. Un ejemplo claro de esta situación fue la entrevista con el equipo de Cubalex, sobre lo que informamos en el apartado 7.

Pese a esas dificultades, hemos contextualizado y clasificado las violaciones. Existen distintas dimensiones: tipo de violación, frecuencia de la violación y cantidad de personas que son objeto de la violación (Stohl et al. 1986). Gran parte de esta clasificación se construyó a partir de las denuncias efectuadas por nuestros entrevistados, desde un paradigma hermenéutico-interpretativo.

Hemos identificado los puntos principales para entender la idea de derechos de baja intensidad. Por ejemplo, una de las formas tradicionales de atemorizar a la población en Cuba es encarcelarlos por un periodo corto, dos o tres días. El acusado no recibe ninguna información, no conoce la causa de su detención ni los procesos consiguientes a su encarcelación. Se le anula su derecho de información, se rebaja su identidad de persona y se lo destrata en su dignidad. Recientemente, este tipo de detenciones se producen con mayor frecuencia por lo que determinados ciudadanos cubanos ven su vida cotidiana interrumpida constantemente por estas «visitas» de la Seguridad del Estado. En suma, teniendo presente el rigor científico que merece cualquier investigación, este escrito surge de entrevistas individuales, sistematizadas, pero cada una de ellas fue tratada como un estudio de caso.

\section{Legalidad ignorada}

En abril de 2019 entró en vigor una nueva Constitución en Cuba, aprobada en un referéndum en febrero. "La nueva Constitución cubana trata de consolidar y dar continuidad a un sistema socialista, democrático, próspero y sostenible. Consta de un Preámbulo y 229 artículos, divididos en 12 títulos, 24 capítulos y 16 secciones. Los fundamentos políticos del Estado socialista y revolucionario permanecen invariables»(Berg-Rodríguez 2019, 940). El artículo primero sostiene que Cuba es un estado socialista de derecho y justicia social, democrático, independiente y soberano. El artículo 4 dice que la defensa de la patria socialista es el más grande honor y el deber supremo de cada cubano. El sistema socialista que refrenda esta Constitución es 
irrevocable. Los ciudadanos tienen el derecho de combatir por todos los medios, incluyendo la lucha armada, cuando no fuera posible otro recurso, contra cualquiera que intente derribar el orden político, social y económico establecido por esta Constitución. El articulo 5 afirma que el Partido Comunista de Cuba, único, martiano, fidelista, marxista y leninista, vanguardia organizada de la nación cubana, sustentado en su carácter democrático y la permanente vinculación con el pueblo, es la fuerza política dirigente superior de la sociedad y del Estado.

En el Capítulo II se describen los derechos. Es importante la asunción del vocablo derechos humanos por primera vez desde el periodo posterior a 1959 (Prieto 2019, 55). El artículo 51 afirma que las personas no pueden ser sometidas a desaparición forzada, torturas ni tratos o penas crueles, inhumanas o degradantes y el artículo 52 dice que las personas tienen libertad de entrar, permanecer, transitar y salir del territorio nacional, cambiar de domicilio o residencia, sin más limitaciones que las establecidas por la ley. El artículo 54 afirma que el Estado reconoce, respeta y garantiza a las personas la libertad de pensamiento, conciencia y expresión. Todo ello muestra una peculiaridad de las características del régimen cubano y las contradicciones evidentes entre la realidad política y la interpretación de la norma jurídica. Rojas $(2017,29)$ recuerda que el artículo $62^{\circ}$ establece que las libertades ciudadanas no pueden ser ejercidas contra lo establecido en la Constitución ni contra la decisión del pueblo cubano de construir el socialismo y el comunismo. Una jaula de hierro para cualquiera que intente una alternativa política. Incluso la objeción de conciencia no es aceptada legalmente (Berg-Rodríguez $2019,941)$. Prieto $(2019,58)$ señala que se constatan en el texto nuevos derechos, entre ellos: al libre desarrollo de la personalidad, a la intimidad, a la información veraz, al disfrute de los bienes de su propiedad, pero no se ha adjuntado la instrumentación legal que asegure su ejercicio.

La Constitución reconoce también garantías de los derechos y establece la estructura del Estado (Granma 2019). Es relevante la presencia de una referencia directa a la obligación del Estado de garantizar los derechos humanos, un avance respecto a la constitución anterior (Bobes 2019, 32). Repasar los principales artículos de la Constitución es importante porque Cuba se ha caracterizado por intentar mantener una apariencia de legalidad. De todas maneras, Cuba es un caso más que confirma que no existe relación entre los tratados que se ratifican o las leyes que se sancionan y la protección de los derechos humanos. Lo que Landman (2004) dividió en derechos humanos en principio y en la práctica. 
Históricamente cuando se apresaban opositores, se simulaba un juicio nombrando fiscales y se designaban defensores de oficio (Lanza 2018). Esto iba acompañado de la ausencia de rendición de cuentas de las instituciones públicas, datos poco confiables de la Oficina Nacional de Estadística e Información, y la opacidad general de las condenas (Azor 2018, 73-76) Ante tanta manipulación histórica de la información, la reciente expansión de las redes sociales en Cuba dificulta cada vez más que el gobierno aparente una realidad que no existe. Sin embargo, las continuas y crecientes detenciones reflejan la omnipotencia y el desinterés del gobierno, que no modifica sus acciones por las consecuencias que podría tener el conocimiento sobre violaciones de derechos humanos, ni se preocupa por disimular su propia ilegalidad. En realidad, el gobierno ha formado un aparato represivo que permanece intacto para defender su naturaleza comunista y que descansa en el Ministerio del Interior (MININT) como explicamos a continuación.

La presunción de que los estados son responsables de proteger los derechos humanos de su población se sustenta en la teoría política clásica sobre la soberanía. Sin embargo, existe un dilema ya que el estado es el que protege los derechos humanos, pero puede convertirse en el violador más cruel de esos derechos. El soberano, a quien la sociedad transfiere poder para asegurar la supervivencia, es responsable por los actos cometidos por sus agentes. Esta visión se basa en la constatación que, en muchos casos, no es el Estado el que directamente propicia los abusos en los derechos ciudadanos, sino suele suceder que los realiza por medio de funcionarios directamente, o a través de agentes encubiertos, como son los grupos paramilitares. En Cuba no hay espacio para acciones individuales de los funcionarios. La verticalidad entre las máximas autoridades y sus subordinados es férrea. Ningún empleado del Estado se animaría a interpretar por sí mismo, o desafiar, las órdenes emanadas de los mandos superiores. Es el mismo Estado, a través de sus agentes de la seguridad del MININT el que viola los derechos humanos de los cubanos.

\section{Derechos humanos y seguridad}

Cuando se utiliza el término seguridad, en general se refiere a dos conceptos diferentes. Uno, define el instrumento público para asegurar externamente al Estado de agresiones probables al territorio, la soberanía o la forma de vida de una población. Más específicamente, es aquello que determina la función de la política de defensa de una 
nación. Por otra parte, el concepto se utiliza para las políticas internas, supuestamente garantizadas por los distintos cuerpos de policía. En el caso de Cuba, formalmente, hay una división entre las FAR, las Fuerzas Armadas Revolucionarias, que repelen agresiones externas y las tareas del MININT, por medio de un cuerpo policial.

En 1959, se crea el Ministerio de las Fuerzas Armadas Revolucionarias (MINFAR) y desde entonces hasta su asunción como Jefe de Estado, Raúl Castro fue puesto a su cargo. El Departamento de Información e Investigaciones de las FAR se ocupa de enfrentar actividades subversivas o contra-revolucionarias. En 1961 se crea el Ministerio del Interior que cuenta con el Departamento de Seguridad del Estado. En 1962, se crea la Dirección de Contrainteligencia de las FAR. Todos estos organismos trabajan de manera muy cercana con los Comité de Defensa de la Revolución, lo cual facilitó el control sobre la vida de los ciudadanos (Ecu Red 2019).

Por lo tanto, de las tareas de control, persecución, encarcelamiento y amedrentamiento de la población, se ha ocupado históricamente el MININT. En las entrevistas realizadas en Cuba para esta investigación, los militares entrevistados aseguraron que las fuerzas armadas nunca reprimieron a la población. Sin embargo, varios entrevistados que no pertenecían a las FAR, explicaron que las autoridades de ese ministerio son militares. Un entrevistado explicó que un mismo oficial puede presentarse con uniforme de las FAR o del MININT. Ello daría cuenta de una segmentación de las fuerzas armadas entre quienes se ocupan de las tareas asignadas a las FAR y aquellos que controlan a los ciudadanos, y al mismo tiempo, una superposición de tareas.

En realidad, las FAR se han convertido en administradoras de la economía cubana. A partir del período especial, pasaron a gestionar el turismo, el mercado interno de divisas (las tiendas de recuperación de divisas y las casas de cambio), el transporte aéreo, la minería, biomedicina y exportaciones de tabaco. Se calcula que las FAR controlan 844 empresas (Aznarez 2007). En 2017, la publicación online Cubanet difundió la lista de hoteles y empresas prohibidas para los estadounidenses por ser consideradas establecimientos militares (Cubanet 2017). El Grupo de Administración Empresarial SA (GAESA) controla entre el 50 y el $80 \%$ de la recaudación empresarial (Aznarez 2015). GAESA incluye empresas turísticas, comercios, tiendas recaudadoras de divisas, comunicaciones y producción agropecuaria. El incremento de su rol económico implicó un proceso de desmilitarización de las fuerzas ya que su entrenamiento militar pasó a un segundo plano para poder ocuparse de las tareas económicas. Es probable que el gobierno haya entendido que las 
consecuencias del embargo estadounidense, después de la caída de la Unión Soviética, eran un desafío más real que la invasión militar por parte del «Imperio».

Por su rol en la Revolución, sus actividades de solidaridad internacional y su papel en el período especial, además de su no involucramiento en tareas de represión interna, los miembros de las FAR son queridos y respetados entre la mayor parte de la población. La institución es considerada como una de las más eficientes y leales. Esta percepción se confirmó en las entrevistas realizadas, ya que nuestros interlocutores consideraron que las FAR deberían ser el actor central en el proceso de «actualización» del modelo económico, ya que por su papel en el período especial habían adquirido una mayor conciencia de los déficits que ha enfrentado históricamente la Revolución cubana.

Una de las tantas contradicciones que existen en Cuba es la percepción de las FAR como una institución cercana al pueblo, cuando en realidad muy poco se sabe de la situación interna de las fuerzas. En realidad, la baja oficialidad es parte de la ciudadanía de a pie, mientras que la jerarquía disfruta, según varios ex militares, de beneficios exclusivos. Una de las características del gobierno es que, como todo régimen autoritario, no consulta sus decisiones ni rinde cuentas.

En América Latina, un recurso para revertir el autoritarismo ha sido el establecimiento de accountability. Sin una traducción exacta, esta acción implica tanto un mecanismo legítimo de control sobre los actos de gobierno por parte de grupos de la sociedad civil, como una responsabilidad de los funcionarios públicos por rendir cuentas por el ejercicio de sus funciones. Esto no se cumple en Cuba, y mucho menos en las FAR, ni en su papel de fuerzas armadas ni en su papel empresarial. Con la justificación de evitar que cualquier información caiga en manos de los EE.UU., el gobierno cubano oculta más allá de lo necesario. Entre lo que oculta está el tema de las violaciones de los derechos humanos.

\section{La cuestión de los «regulados»}

Los «regulados», medio por el cual las autoridades restringen la libre circulación de activistas, periodistas y opositores en general, es un procedimiento que carece de cualquier legitimidad. No surge de ningún registro legal ni documento que justifique la imposibilidad de viajar al exterior de Cuba. Es una amenaza verbal que no se sostiene en un reglamento, ni en un proceso judicial. Comenzó a aplicarse desde 2016, aunque desde 2018 la estrategia de informar acerca de 
su estatus de «regulados» en el momento de pasar por la ventanilla de Inmigración se ha vuelto más habitual.

No obstante, las autoridades se justifican en base a leyes que son terriblemente ambiguas. La libre circulación de personas, consagrada tanto por el artículo 13 de la Declaración Universal de Derechos Humanos como por el artículo 52 de la Constitución cubana, es un derecho. La «regulación» se sustenta en un criterio que figura en el Código Penal. El código establece la peligrosidad predelictiva que permite detener o castigar un delito antes que se cometa. Definidas en los artículos 73 al 84 del Código penal cubano, pueden llevar condenas de 1 a 4 años de cárcel. Sin embargo, según el artículo 25 de la Ley Migratoria «toda persona que se encuentre en el territorio nacional» puede salir del país a menos que se halle «sujeto a proceso penal» (Ley n. 1312).

La explicación acerca de cuáles son las razones de defensa y seguridad nacional, o de interés público, que justifican regular a un ciudadano cubano, no existen. No hay una reglamentación accesoria que identifique esos causales. Por lo tanto, todo queda en manos de una caprichosa decisión de las autoridades migratorias, que responden al MININT. La Ley de Migración, Ley n. 1312, incorporada por el Decreto-Ley n. 302, dispone las causales por las que una persona no puede salir del país. Los incisos d y h hacen una determinación muy abierta de cuáles son las razones de defensa y seguridad nacional que aconsejan que una persona no pueda salir del país o cuáles son las razones de interés público para tomar esa decisión.

La persona regulada desconoce los motivos de su imposibilidad de trasladarse al exterior, la duración de esa medida o las consecuencias que sobrelleva. El periodista Boris González Arenas comentó a la publicación 14 y medio: "La Constitución cubana actual tiene un instrumento que no es el habeas data [aunque se asemeja], pero por el cual uno puede pedir al Estado la información que tiene sobre él. Lo solicité a Inmigración para saber la razón de mi 'regulación'. Por supuesto no hubo respuesta» (Escobar 2019). A principios de 2020 este periodista fue encarcelado en varias oportunidades.

Se supone que un regulado puede encaminarse a la Dirección de Identificación, Inmigración y Extranjería, en el mismo edificio donde se otorga el carné de identidad, ambas pertenecientes al MININT. Pero la experiencia de este periodista grafica claramente lo irrelevante de ese procedimiento.

Es seguramente por ello que los regulados no son encarcelados, pues la privación ilegítima de la libertad recae sobre los agentes del Estado. Mayormente, no son apresados. Pero sus derechos son vulnerados. 
Todo esto es más incomprensible e incoherente si recordamos que el propio Código Penal fija, en el capítulo IV, Delito contra la libre emisión del pensamiento, por medio del artículo 291, inciso 1, lo siguiente: «El que, en cualquier forma, impida a otro el ejercicio del derecho de libertad de palabra o prensa garantizado por la Constitución y las leyes, es sancionado con privación de libertad de tres meses a un año o multa de cien a trescientas cuotas o ambas».

Estos regulados no son sometidos a juicio, ni se les informa de la falta cometida para impedir su salida al exterior. La comunidad internacional no reacciona ante estos hechos de privación de derechos. Mayormente son los mismos cubanos, muchos de ellos radicados en el exterior, quienes denuncian estas faltas graves. ${ }^{1}$ Uno de los «regulados», Osmel Ramírez (2019), afirma: «No tengo ningún proceso judicial pendiente, no me dicen exactamente por qué» y agrega que han intentado condicionarle el levantamiento de la prohibición de viajes a «que firme algún documento o haga algún video diciendo que no voy a participar en la política opositora en el extranjero, si acaso me quedara en algún momento» (ADN Cuba 2020).

El temor de activistas, periodistas, artistas, es que finalmente se les procese por medio de la Ley 88, conocida como "Ley Mordaza». La Ley 88 de Protección de la Independencia Nacional y la Economía de Cuba, de febrero de 1999, fija penas de privación de libertad de ocho a veinte años a quienes actúen en favor de EE.UU. En realidad, esta ley ha servido para coartar y criminalizar todo ejercicio de libertad de expresión. El presidente del Tribunal Supremo Popular de Cuba, Rubén Remigio Ferro, amenazó con aplicar la Ley n. 88 que contiene apartados destinados a reprimir al periodismo independiente en el país (INFOBAE 2019).

\section{Detenciones arbitrarias}

Una fuente confiable para recabar datos acerca de los abusos contra los derechos humanos, son los informes de Amnistía Internacional. Desde 2007 dan cuenta del incremento de actos de repudio realizados por pequeños grupos de personas afines al gobierno contra aquellos identificados como opositores. El informe de Amnistía

1 Por ejemplo, Los «Regulados» es una web participativa que busca visibilizar los casos de esos cubanos a los que el gobierno les impide salir del país por razones políticas. Véase: https://adncuba.com/noticias-de-cuba/derechos-humanos/los-regulados. 
considera estos actos de repudio como una tortura psicológica (Amnistía Internacional 2018).

El análisis de los informes de Amnistía entre 2006 y 2018 indica un incremento en las violaciones a los derechos humanos (Amnistía Internacional 2018). Por ejemplo, en 2008 se impidió a varias personas participar en una reunión deteniéndolas por unas horas. Este es un método que la seguridad del Estado utiliza con una frecuencia casi cotidiana2. En algunos casos, los ciudadanos serán detenidos por unas horas y, en otros, los agentes de la seguridad les impedirán salir de sus hogares vulnerando la libertad de tránsito. En el año 2012, cuando los cubanos comenzaban a descubrir internet, la entonces bloguera Yoani Sánchez no pudo viajar a Brasil para asistir a una reunión. Eran los comienzos de la política de los «regulados».

El informe de 2015 de Amnistía contabilizaba 1400 detenciones por motivos políticos. La mayoría de estos ciudadanos estuvieron detenidos entre 1 y 30 horas. En 2016, cuando muere Fidel Castro, el grafitero Danilo Maldonado fue arrestado por escribir en un muro de La Habana: «Se fue». El informe de la Comisión Interamericana de Derechos Humanos registra distintos casos de persecución hacia periodistas de medios independientes como Periodismo de Barrio, Diario de Cuba, La Hora de Cuba, Cocodrilo Callejero, 14yMedio, y hacia directivos y periodistas del Instituto Cubano por la Libertad de Expresión y Prensa. Iris Mariño contabilizó 22 casos de hostigamiento hacia ella con detenciones e interrogatorios donde no había ninguna oficial mujer (Lanza 2018). Entre febrero y marzo de 2018, 16 periodistas fueron impedidos de viajar al exterior. Asimismo, la Comisión Interamericana de Derechos Humanos recibió informes sobre deportaciones internas (Lanza 2018). En Cuba existen regulaciones internas para la libre movilización de ciudadanos, especialmente hacia La Habana. Muchos activistas o periodistas independientes son imposibilitados de viajar libremente por la isla. Human Rights Watch (2019: 1) denuncia que:

El gobierno sigue llevando a cabo detenciones arbitrarias para hostigar e intimidar a críticos, activistas independientes, opositores políticos y otras personas. La cantidad de detenciones arbitrarias de corta duración, que aumentó de manera drástica entre 2010 y 2016 — de un promedio mensual de 172 incidentes a 827-, empezó a descender durante 2017, según datos de la Comisión Cubana de Derechos Humanos y Reconciliación Nacional, una organización

2 Las autoras de este ensayo fueron demoradas en el aeropuerto de La Habana, sin ninguna explicación ni respuesta. 
independiente de derechos humanos que es considerada ilegal por el gobierno.

Este descenso también lo registra el Observatorio Cubano de Derechos Humanos con sede en Madrid, que desde 2014 publica informes anuales online. El siguiente cuadro muestra las cifras que ofrece el Observatorio sobre detenciones arbitrarias.

Tabla 1

\section{Detenciones Arbitrarias en Cuba}

\begin{tabular}{|c|c|c|}
\hline Año & Detenciones Arbitrarias & Mujeres detenidas \\
\hline 2014 & 8.970 & 5.737 \\
\hline 2015 & 8.314 & 4.006 \\
\hline 2016 & 9.351 & 5.383 \\
\hline 2017 & 4.821 & 3.333 \\
\hline 2018 & 2.525 & 1.700 \\
\hline $2019 *$ & 1.729 & n.a. \\
\hline
\end{tabular}

Fuente: Elaboración propia a partir de los datos de los informes del Observatorio Cubano de Derechos Humanos (2014-2019).

En general, las mujeres sufren más detenciones que los hombres y esto se debe, principalmente, al movimiento de las Damas de Blanco.

En 2017 y 2018 se registran detenciones de artistas como Tania Bruguera, Danilo Maldonado (conocido como El Sexto) y artistas integrantes del Movimiento San Isidro, opositores al Decreto 349 de abril de 2018 (Hernández Busto 2018).

En suma, con el fin de preservar la revolución, el régimen estigmatiza toda opinión contraria a los preceptos del gobierno como un atentado a la estabilidad y seguridad de Cuba, y con ello justifica la aplicación de medidas represivas. Comparando con otras experiencias latinoamericanas, sus formas de acallar a la disidencia y eliminar a los elementos nocivos para el criterio oficial son menos crueles que las experimentadas en dictaduras como las de Argentina o Chile. De todas formas, ¿se pueden considerar abusos contra los ciudadanos de baja intensidad? Veamos otros ejemplos que permitirán responder más objetivamente a esta cuestión. 


\section{Las Damas de Blanco}

Las Damas de Blanco surgen espontáneamente en 2003, luego del encarcelamiento de sus maridos o hijos, en lo que se conoce como la Primavera Negra de Cuba.

El gobierno cubano preocupado por la fuerza del movimiento opositor organizó una redada el 18 de marzo de 2003 que culminó con la detención de 75 opositores. Durante el mes de abril, en juicios sumarios, los detenidos fueron condenados a prisión con sentencias que iban de los 6 a los 30 años. Algunos de los arrestados fueron condenados a 28 años de cárcel por atentar contra el Estado y socavar los principios de la Revolución.

La denominada «Primavera Negra» fue una reacción al éxito del Proyecto Varela, un proyecto de ley para la expansión de los derechos y las libertades. Cualquier proyecto de ley con un número superior a 10.000 firmas obligaba a la Asamblea Nacional del Poder Popular a tomarlo en cuenta. El proyecto, formulado por Oswaldo Payá Sardiñas, logró la firma de 25.000 cubanos.

Como consecuencia de las detenciones y las posteriores condenas, surgieron las Damas de Blanco. Todos los domingos se reúnen para ir caminando pacíficamente hacia la iglesia. Las más conocidas son las Damas que residen en La Habana que intentan ir a la iglesia de Santa Rita en el barrio de Miramar, pero hay Damas en casi todos los pueblos y ciudades del país.

En el año 2010, 52 de los 75 presos fueron desterrados a España y 13 se quedaron en Cuba. Las Damas siguen saliendo cada domingo porque se han convertido en una voz en la lucha por la libertad. La imagen de este grupo de mujeres ha sido perjudicada por enfrentamientos y pugnas internos -algunos de ellos inducidos y/o potenciados por la labor de agentes del gobierno- y por la propaganda negativa del gobierno cubano, que las señaló como agentes de los intereses de EE.UU.

En 1977, otro grupo de mujeres había salido a la calle reclamando por sus hijos. Los militares argentinos las llamaron «viejas locas», pero el mundo las conoce como las Madres de Plaza de Mayo. Eduardo Galeano en su poema "Derecho al delirio» escribió «en Argentina las locas de Plaza de Mayo serán un ejemplo de salud mental porque ellas se negaron a olvidar en los tiempos de la amnesia obligatoria». La fuerte propaganda negativa por parte del gobierno cubano hacia las Damas de Blanco resulta en una muy escasa solidaridad nacional, regional o internacional con ellas, comparado con el enorme caudal de apoyo logrado internacionalmente por las Madres. Un dato curioso 
es que las Madres de Plaza de Mayo tampoco se solidarizan con las Damas, por diferencias ideológicas y por esa arraigada costumbre de defender la revolución cubana como adalid del progreso ciudadano.

Una peculiaridad del régimen cubano es que ha proyectado, especialmente hacia América Latina, una imagen romántica de la Revolución. Por ello, la solidaridad de muchos grupos de izquierda sigue estando con la Revolución, y a los opositores se los considera como un brazo del imperialismo norteamericano. Por lo tanto, no hay lazos de solidaridad entre las Madres de Plaza de Mayo y las Damas de Blanco, a pesar de que los dos grupos luchan contra la represión de las libertades fundamentales.

Tampoco existe mucha simpatía o solidaridad entre los cubanos con las Damas en Cuba, una situación que recuerda a la indiferencia de la mayoría de los argentinos hacia las Madres durante los años de la dictadura. Para explicar esta indiferencia hay que tener en cuenta la exitosa campaña del gobierno contra ellas, el limitado acceso a información externa a la que están sometidos los cubanos y el miedo de los ciudadanos a enfrentarse a la máquina represora. Todo ello conduce a que las Damas sufran fuertes restricciones para expresar sus puntos de vista.

En el apartado siguiente, se refleja otro aspecto de los impedimentos para la libre expresión, vinculado a las artes y el periodismo.

\section{Libertad de expresión}

Durante 2019 se produjo en Cuba un movimiento inesperado, una reacción instintiva generada por los artistas contra el Decreto gubernamental 349, de censura previa a las producciones artísticas. Con la excusa de controlar la calidad cultural del regaetton, el gobierno nombraba inspectores para verificar las obras de arte. Los artistas de distintas expresiones del arte (pintura, escultura, teatro, literatura, música) viabilizaron el descontento de forma activa y organizada (Rojas 2018). Se capitalizó la energía, juntando gente apolítica que desplegó objetivos políticos. Gracias a las acciones de estos artistas, se revirtió el control de la cultura que intentaba implementar el gobierno. Los escritores buscaron sacarse la mordaza, escultores y pintores pelearon por su libertad creativa (Gallo 2019). Realizaron una bienal paralela a la que organizó el gobierno e intentaron captar un público que sorteaba la deslegitimación provocada por las autoridades. Sin embargo, algunos continúan sufriendo encarcelaciones. Otros debieron huir del país. Algunos fueron expulsados de las universidades donde dictaban clases. Otros dejaron de tener apoyo estatal para sus producciones. La 
movilización contra el decreto 349 mostró una vez más que la lucha por la libertad de expresión en Cuba tiene costos.

De acuerdo con el Comité para la Protección de los Periodistas, Cuba es uno de los diez países con mayor censura en el mundo (Lanza 2018). Hay periodistas que son perseguidos. Sus publicaciones en medios alternativos son denunciadas como antirrevolucionarias. No se les deja salir del país. Pese a ello, en los últimos años surgieron numerosos medios que dan cuenta de la vitalidad de estos jóvenes por expresar sus ideas, como 14 y medio, Joven Cuba, On Cuba news, El Estornudo, El Toque, Periodismo de Barrio. Todos los periodistas saben los riesgos que corren al propagar sus ideas en publicaciones no aceptadas por el oficialismo. Es llamativo que muchas de estas publicaciones no son políticas, sin embargo, están igualmente sujetas a represión.

Twitter se ha convertido en un medio relativamente económico y eficiente que permite a los cubanos expresar ideas. Díaz Canel permitió utilizar este recurso en diciembre de 2018. Instó a sus ministros a abrir sus respectivas cuentas para comunicarse con los ciudadanos. Sin embargo, cuando las críticas eran evidentes, muchos de ellos bloquearon a los twitteros. Por cierto, la mayoría de las cuentas no van más allá de temas muy cotidianos. Por ejemplo, la campaña \#BajenlosPreciosdelnternet no produjo una discusión sobre la libertad de expresión, sino por el costo del servicio. El gobierno mantiene precios altos no solo por los costos sino también para poder controlar el acceso a internet. Es otra forma de coerción, sutil, pero efectiva.

¿Estamos ante otra forma de atropellar los derechos humanos del modo de baja intensidad? No diría lo mismo, seguramente, la abogada Laritza Diversent, que tuvo que exilarse ante la violencia con la que fue destruida su institución (Pentón 2017). CUBALEX era una organización no gubernamental que brindaba servicios de asistencia y asesoría legal gratuita a víctimas de violaciones de derechos humanos y grupos en situación de vulnerabilidad en Cuba. En septiembre de 2016 miembros de la Seguridad del Estado realizaron un registro y decomisaron documentos, destruyeron ordenadores y humillaron a las personas que encontraron en la institución. Algunos de ellos fueron obligados a desnudarse frente de los investigadores y los miembros de la Seguridad. Catorce miembros de CUBALEX se terminaron refugiando en EE.UU., entre ellos, Laritza Diversent ${ }^{3}$.

3 En abril de 2016 visitamos la sede de CUBALEX en la localidad El Calvario, municipio de Arroyo Naranjo de La Habana, y conversamos con varios miembros de la ONG. No sólo prestaban servicios a activistas perseguidos por sus ideas políticas sino también a mujeres víctimas de violencia de género o menores víctimas de violencia familiar. 
Tal como se evidencia en los comentarios siguientes recopilados en nuestras entrevistas, periodistas, artistas y activistas políticos dan cuenta de la persecución constante que sufren por parte de las autoridades. Un joven artista más comprometido desde las movilizaciones contra el decreto 349 expresó: "La oposición se enfrenta a un gobierno profundamente opresivo; te sacan tu identidad ciudadana, te criminalizan, te convierten en un delincuente. Es un costo político y social muy alto, por eso hay miedo. La comunidad está resquebrajada». Un joven periodista independiente nos comentaba que los opositores se quedan muy solos. Muchas veces por miedo sus amigos o sus familias los van dejando solos. En otros casos, estos jóvenes se enfrentan a sus padres quienes siguen defendiendo la Revolución. Una de las entrevistadas más jóvenes ${ }^{4}$ nos comentaba que creía que sus padres se aferraban a la idea de la Revolución porque enfrentar el fracaso de esa utopía significaba enfrentar el fracaso de sus propias vidas.

Desde una mirada más sofisticada, uno de ellos nos dijo: «es un daño antropológico. A mis padres les extirparon la capacidad crítica». Otro entrevistado, con más frustraciones, aseveró: «el [decreto] 349 muestra que el legado de la revolución es la mediocridad, a ellos les conviene la mediocridad y hacer sentir que lo que se tenga es un regalo para agradecer toda la vida».

En las entrevistas realizadas en mayo de 2019 percibimos un cambio muy importante en estos jóvenes. Una de ellas lo resumió: "antes éramos apolíticos, pero llego Twitter y cambiamos». Los Twitteros están seguros de que los «ministros leen, pero no debaten».

Twitter es la vidriera, junto con Facebook, donde se comunican las detenciones arbitrarias, las prohibiciones de viajes al exterior, las golpizas en manifestaciones o la intimidación a las Damas de Blanco. Y es también donde los cubanos se ríen de la torpeza de sus dirigentes y se burlan de sus propias luchas cotidianas.

Esta transparencia inesperada complica al gobierno cubano, para el cual el secretismo ha sido siempre la médula de su poder. Más aún cuando el presidente no es un Castro y no tiene ni una pizca de carisma y, con las penurias económicas, cada vez es probable que tenga menos legitimidad.

Diaz Canel impuso el hashtag \#SomosContinuidad, lo que demuestra su distorsionada percepción de la realidad cubana. Uno de los entrevistados en nuestro viaje a La Habana de julio de 2019 sentenció: "estamos hartos de continuidad, queremos cambio». No

${ }^{4}$ Los jóvenes entrevistados tenían entre 25 y 36 años. 
sólo los opositores perciben la necesidad de cambio. Una mirada a la situación social muestra que la Revolución está fallando en varios frentes.

De acuerdo con el Observatorio de Derechos Sociales de Cuba, el $55,4 \%$ de los hogares recibe menos de 100 dólares al mes. El 70\% no cuenta con suministro permanente de agua. Un 32\% dice tener agua entre cuatro y cinco días por semana y un $28 \%$ menos de tres días a la semana. El $80 \%$ de la población no tiene suministro eléctrico continuo. El $42,3 \%$ de las personas que necesitaron medicamentos no pudieron conseguirlos. Finalmente, el $78,6 \%$ asegura que no recibe ningún tipo de asistencia social por parte del estado (Observatorio Cubano de Derechos Humanos 2019).

En este contexto, la continuidad que propone el presidente es inexplicable no sólo para los opositores, sino quizás también para los que apoyan el gobierno.

Recientemente, Amnistía Internacional pidió a Miguel Díaz-Canel permitirle observar el juicio de José Daniel Ferrer García, líder del grupo de oposición política Unión Patriótica de Cuba (Unpacu). Ferrer fue detenido el 1 de octubre de 2019 y en abril de 2020 permanece incomunicado. "Amnistía Internacional ha observado juicios en múltiples países desde hace décadas como una herramienta que permite monitorear la situación de derechos humanos en un caso específico y de manera objetiva e imparcial. En consonancia con esta práctica, solicitamos al presidente Díaz-Canel que permita nuestro acceso a Cuba», dijo Erika Guevara-Rosas, directora para las Américas de la Secretaría Internacional de Amnistía Internacional (Deutsche Welle 2019). El diario Granma, órgano oficial del Partido Comunista de Cuba, calificó a Ferrer como "agente asalariado al servicio de EE.UU., con una larga trayectoria de acciones de provocación». La prensa oficial presenta a Ferrer como violento, agresor, ladrón y estafador (Bohemia 2019).

\section{Conclusiones}

Todos estos análisis y testimonios nos llevan a replantear nuestra pregunta inicial: ¿Estamos ante abusos contra los derechos humanos de baja intensidad? O en realidad, aunque no tengan el carácter masivo de las dictaduras latinoamericanas, ¿son abusos de alta intensidad contra los derechos ciudadanos?

La literatura recuerda que el movimiento por los derechos humanos surgió como un valor universal luego de la Segunda Guerra Mundial, 
como respuesta al horror del Holocausto, el autoritarismo político y la discriminación racial y étnica. El movimiento por los derechos humanos se fortalece para evitar las patologías políticas que atentan contra los seres humanos, promoviendo una convivencia digna en el Estado. El Estado es responsable de brindar una protección a sus ciudadanos. Y este concepto se universaliza, no sólo para las democracias occidentales, sino como un valor filosófico extendido a toda la humanidad.

En Cuba, la interpretación de los derechos humanos es sesgada. Tal como lo expresa Human Rights Watch $(1999,3)$ :

Con el Código Penal en mano, los funcionarios cubanos cuentan con amplios poderes para reprimir internamente a la oposición pacífica al Gobierno, mientras afirman su respeto al Estado de Derecho en los foros internacionales. La legislación penal cubana está concebida para aplastar la disidencia interna y mantener en el poder al gobierno actual por medio de la restricción rigurosa de las libertades de expresión, asociación, reunión, prensa y movimiento. En una declaración extraordinaria de junio de 1998, el Ministro de Justicia cubano Roberto Díaz Sotolongo justificó las restricciones a la disidencia en Cuba explicando que, al igual que España ha promulgado leyes para proteger de las críticas al monarca, Cuba tenía motivos para proteger a Fidel Castro de las críticas, dado que cumplía una función similar, la de «rey» de Cuba.

Las violaciones a los derechos humanos en Cuba son cotidianas. Aquellos ciudadanos que piensan diferente viven con miedo. Expresar una opinión distinta, reunirse con asociaciones o movimientos opositores tiene un costo: perder el trabajo, perder los pocos beneficios que pueden haber logrado, perjudicar a un familiar, no poder ingresar a la universidad, ir preso o no poder salir del país. Que las violaciones no sean masivas no significa que la intensidad de las mismas no abrume a los ciudadanos. Es verdad que, comparadas con el genocidio en Guatemala, en Argentina o en Chile, las violaciones son menores en número y perversión. No obstante, no es una cuestión de números sino del sufrimiento y temor constante de una amplísima parte de la población.

El Estado cubano garantiza ciertos derechos de sus ciudadanos, a través de un marco legal como la Constitución de 2019, y contradictoriamente viola los derechos de sus ciudadanos habitualmente, obligándolos a aceptar una utopía que movilizó al mundo muchos años atrás. Los condenan cotidianamente a una vida paupérrima, al miedo y al silencio. Amparados en algunas políticas sociales, las autoridades 
implementan acciones represivas, impunes y desmovilizantes de la población.

Los datos que presentamos muestran que, aunque en apariencia se crea que en Cuba hay abusos de baja intensidad de los derechos humanos, la realidad es que los derechos humanos están enterrados y olvidados. Este artículo marca una realidad que la polarización entre una derecha reaccionaria y una izquierda cómplice deja abandonada. Ni las acusaciones muchas veces infundadas, ni las mentiras bien resguardadas, reflejan la vida diaria de los cubanos de a pie que, entre limitaciones materiales y psicológicas, sobreviven en una Cuba que no fue.

\section{Referencias bibliográficas}

ADN Cuba. 2020. «Régimen impide salida del país a miembro de Convivencia», ADN Cuba, 4 de febrero. Acceso el 15 de octubre de 2019. https:// adncuba.com/noticias-de-cuba/regimen-impide-salida-del-pais-miembrode-convivencia

Amnistía Internacional. 2018. Cuba. Acceso el 2 de octubre de 2019. https:// www.es.amnesty.org/en-que-estamos/paises/pais/show/cuba/

Aznarez, Juan J. 2007. "El Ejército controla la economía de Cuba», El País, 2 de noviembre, Acceso el 15 de septiembre de 2019. https://elpais.com/ diario/2007/02/11/internacional/1171148413_850215.html.

Aznarez, Juan J. 2015. "El hombre más buscado de Cuba», El País, 15 de octubre. Acceso el 15 de septiembre de 2019. https://elpais.com/ economia/2015/10/15/actualidad/1444930825_755592.html.

Azor, Marlene. 2018. Violaciones a Derechos Humanos en Cuba (I-V). Acceso el 23 de septiembre de 2019. https://www.cubaencuentro.com/usuarios/ autores/marlene-azor-hernandez.

Beaulieu, Sarah. 2014. Política Cultural y Periodismo en Cuba: Trayectorias cruzadas de la prensa oficial y de los medios independientes (1956-2013), Tesis doctoral, Universidad de Granada.

Berg-Rodríguez, Alexis. 2019. La reforma constitucional en Cuba en el marco de la aplicación provisional del Acuerdo UE-Cuba del 2016, Oñati SocioLegal Series 9, n. 6: 924-950.

Boaventura de Sousa, Santos. 2002. «Hacia una concepción multicultural de los derechos humanos», El Otro Derecho 28, 59-83.

Bobes Cecilia. 2019. "La nueva Constitución cubana en perspectiva comparada. ¿Qué lecciones podemos extraer de las constituciones del socialismo del siglo XXI», en Sergio Ángel y Armando Chaguaceda, editores, Cuba Pos-Castro: ¿Espejismo o Realidad? Miradas diversas sobre una sociedad en transición, 23-39. Bogotá: Universidad Sergio Arboleda.

Bohemia. 2019. Agente asalariado de EE.UU. desenmascarado en tV cubana, 27 Noviembre. Acceso el 13 de octubre de 2019. http://bohemia.cu/ mundo/2019/11/agente-asalariado-de-ee-uu-desenmascarado-en-tv-cubana/. 
Cádena-Iñíguez, Pedro et al. 2017. "Métodos cuantitativos, métodos cualitativos o su combinación en la investigación: un acercamiento en las ciencias sociales», Revista Mexicana de Ciencias Agrícolas 8, n. 7: 16031617.

Castro, Fidel. 1959. Discurso pronunciado por el Comandante Fidel Castro Ruz, a su llegada a la Habana, en cuidad libertad, el 8 de enero de 1959. Acceso el 13 de octubre de 2019.http://www.cuba.cu/gobierno/ discursos/1959/esp/f080159e.html

CUBANET. 2017. ¿Cuáles son los lugares en Cuba que EE.UU. ha prohibido a sus ciudadanos? Acceso el 22 de septiembre de 2019. https://www. cubanet.org/actualidad-destacados/cuales-son-los-lugares-en-cuba-queeeuu-ha-prohibido-sus-ciudadanos/.

Deutsche Welle. 2019. Amnistía pide a Díaz-Canel acceso a Cuba para observar juicio a disidente, 22 de noviembre. Acceso el 25 de septiembre de 2019. https://www.dw.com/es/amnist\%C3\%ADa-pide-a-d\%C3\%ADaz-canelacceso-a-cuba-para-observar-juicio-a-disidente/a-51377066.

Ecu Red. 2019. «Departamento_de_Seguridad_del_Estado_(Cuba)», Acceso el 6 de noviembre de 2019.https://www.ecured.cu/Departamento_de_ Seguridad_del_Estado_(Cuba).

Escobar, Luz. 2019. ««Regulados» en pie de guerra», 14 y Medio.com, 25 de Septiembre. Acceso el 25 de septiembre de 2019. https://www.14ymedio. com/nacional/Regulados-pie-guerra_0_2735726405.html.

Foucault, Michel. 2002. Vigilar y castigar: nacimiento de la prisión, Buenos Aires: Siglo XXI Editores.

Gallo, Rubén. 2019. "Cuba no debe volver a la era de oscurantismo y censura», New York Times, 17 de febrero. Acceso el 25 de septiembre de 2019.https://www.nytimes.com/es/2019/02/17/espanol/opinion/cubadecreto-349.html.

Gills, Barry, Joel Rocamora y Richard Wilson. 1994. Low Intensity Democracy: Political Power in the New World Order. Londres: Pluto Press.

Granma. 2019. Nueva campaña de calumnias de EE. UU. contra Cuba, 20 de noviembre. Acceso el 20 de noviembre de 2019. http://www.granma.cu/ cuba/2019-11-20/nueva-campana-de-calumnias-de-ee-uu-contra-cuba-2011-2019-01-11-39.

Hernández Busto, Ernesto. 2018. ¿Qué es el decreto 349 y por qué los artistas cubanos están en contra? Acceso el 20 de noviembre de 2019. https:// www.letraslibres.com/mexico/cultura/que-es-el-decreto-349-y-por-que-losartistas-cubanos-estan-en-contra

Human Rights Watch. 1999. La maquinaria represiva de Cuba: Los derechos Humanos 40 años después de la Revolución. Acceso el 25 de septiembre de 2019. https://www.refworld.org.es/publisher,HRW , CUB, 57f79452c,0.html.

Human Rights Watch. 2019. "Cuba, eventos de 2018», Informe Mundial 2019. Acceso el 20 de octubre de 2019. https://www.hrw.org/es/worldreport/2019/country-chapters/326036.

INFOBAE. 2019. Alertan a ONU que la aplicación de Ley Mordaza podría desatar otra ola represiva en Cuba, 14 de mayo. Acceso el 18 de septiembre de 
2019. https://www.infobae.com/america/america-latina/2019/05/14/alertana-onu-que-la-aplicacion-de-ley-mordaza-podria-desatar-otra-ola-represivaen-cuba/.

Jelin, Elizabeth. 2003. «Los derechos humanos y la memoria de la violencia política y la represión: la construcción de un campo nuevo en las ciencias sociales», Cuadernos del IDES 2, Buenos Aires: Instituto de Desarrollo Económico y Social.

Kruijt, Dirk. 2001. "Low Intensity Democracies: Latin America in the Postdictatorial Era», Bulletin of Latin American Research 20, n. 4: 409-430

Landman, Tom. 2004. «Measuring Human Rights: principle, practice, and policy», Human Rights Quarterly 26, n. 4: 906-931.

Lanza, Edison. 2018. Informe especial sobre la situación de la libertad de expresión en Cuba. Comisión Interamericana de Derechos Humanos, Washington, D.C.: OEA. Acceso el 2 de septiembre de 2019. http://www. oas.org/es/cidh/expresion/docs/informes/Cuba-es.pdf.

Leis, Héctor R. 1989. El movimiento por los derechos humanos y la política argentina. Buenos Aires: CEAL

Observatorio Cubano de Derechos Humanos (2014-2019). Informes de Derechos Humanos. Acceso el 22 de octubre de 2019. https://observacuba. org/informes-ddhh/

Observatorio Cubano de Derechos Humanos (2019). OCDH denuncia que más de la mitad de los cubanos vive por debajo del umbral de pobreza. Acceso el 22 de octubre de 2019. https://observacuba.org/ ocdh-denuncia-que-mas-de-la-mitad-de-los-cubanos-vive-por-debajodel-umbral-de-pobreza/.

O'Donnell, Guillermo. 1993. "On the State, democratization and some conceptual problems. (A Latin American view with glances at some Postcommunist countries)», Working Paper \#192, Notre Dame: Kellogg Institute.

Pentón, Mario. 2017. Laritza Diversent y Cubalex comienzan su vida en el exilio. Acceso el 22 de octubre de 2019. https://www.14ymedio.com/ nacional/Laritza-Diversent-Cubalex-comienzan-exilio-Miami-cuba-cubanosEstados_unidos-refugio_politico-asilo_0_2211378852.html.

Prieto, Martha. 2019. "Las novedades de la constitución cubana aprobada el 24 de febrero de 2019», Cuadernos Manuel Giménez Abad 17: 53-62.

Quevedo, Jorge. 2014. Derechos humanos en Cuba. No es cosa de juegos. Acceso el 15 de octubre de 2019. http://www.granma.cu/granmad/secciones/cdh61/ obra/a01.html.

Ramírez, Osmel. 2019. "Los «Regulados»», ADN Cuba, 14 de agosto, Acceso el 22 de octubre de 2019. https://adncuba.com/noticias-de-cuba/derechoshumanos/los-regulados-osmel-ramirez-alvarez

Rojas, Rafael. 2017. "¿Es posible ampliar los derechos civiles y políticos en Cuba sin revocar el socialismo?», Cuban Studies 45: 28-35.

Rojas, Rafael. 2018. "Artistas contra un decreto», Letras Libres, 8 de diciembre. Acceso el 15 de octubre de 2019. https://www.letraslibres.com/mexico/ cultura/artistas-contra-un-decreto. 
Stefanoni, Pablo. 2013. «No me arriesgo a predecir el futuro de Cuba. Entrevista con Leonardo Padura», Nueva Sociedad 247: 138-151.

Stohl, Michael, David Carleton, George Lopez y Stephen Samuels. 1986. "State violation of human rights: issues and problems of measurement», Human Rights Quarterly, 8, n. 4: 592-606. 


\section{Copyright}

Deusto Journal of Human Rights / Revista Deusto de Derechos Humanos is an Open Access journal; which means that it is free for full and immediate access, reading, search, download, distribution, and reuse in any medium only for non-commercial purposes and in accordance with any applicable copyright legislation, without prior permission from the copyright holder (University of Deusto) or the author; provided the original work and publication source are properly cited (Issue number, year, pages and DOI if applicable) and any changes to the original are clearly indicated. Any other use of its content in any medium or format, now known or developed in the future, requires prior written permission of the copyright holder.

\section{Derechos de autoría}

Deusto Journal of Human Rights / Revista Deusto de Derechos Humanos es una revista de Acceso Abierto; lo que significa que es de libre acceso en su integridad inmediatamente después de la publicación de cada número. Se permite su lectura, la búsqueda, descarga, distribución y reutilización en cualquier tipo de soporte sólo para fines no comerciales y según lo previsto por la ley; sin la previa autorización de la Editorial (Universidad de Deusto) o la persona autora, siempre que la obra original sea debidamente citada (número, año, páginas y DOI si procede) y cualquier cambio en el original esté claramente indicado. Cualquier otro uso de su contenido en cualquier medio o formato, ahora conocido o desarrollado en el futuro, requiere el permiso previo por escrito de la persona titular de los derechos de autoría. 